\title{
GPPS-BJ-2019-0081
}

\section{Aero-thermal Performance of Coolant Released from Suction Surface in a High-Pressure Turbine Cascade}

\author{
Zuhao Liu \\ Peking University \\ ZuhaoLiu@pku.edu.cn \\ Beijing, China
}

\author{
Chao Zhou* \\ Peking University \\ czhou@pku.edu.cn \\ Beijing, China
}

\author{
Kai Zhou \\ Peking University \\ zhoukaigo@126.com \\ Beijing, China
}

\begin{abstract}
Controlling the tip leakage flow is crucial for improving the aerodynamic and thermal performance of unshrouded highpressure turbines. The advantages of a single cooling hole to release coolant from suction surface were sought by numerical method in the cases of flat tip blade. Compared with no coolant case, the coolant cases exhibited significant differences on the intensity and evolution of tip leakage vortex and corresponding aero-thermal performance of turbine depending on locations to release coolant and blowing ratios of coolant. The impact of five axial locations to release coolant, namely $10 \%, 20 \%, 30 \%, 40 \%$, and $50 \%$ axial chord of blade respectively, was studied. And the impact of three blowing ratios of coolant, namely $0.7,1.4$, and 2.1 , was investigated. Within the scope of the current study, the best aerodynamic effect was achieved when the coolant was released before $30 \%$ axial chord of blade. The aerodynamic effect became worse when the coolant was released after that place. This phenomenon implied that it was a better strategy to release coolant at the initial period of evolution of tip leakage vortex. With regard to the cases with coolant released at $20 \%$ axial chord of blade, the mixed-out loss caused by tip leakage vortex reduced with the increasing of blowing ratio from 0.7 to 2.1. Last but not least, the thermal performance of suction surface of blade was improved with the increasing of blowing ratio.
\end{abstract}

\section{NOMENCLATURE}

$$
\begin{aligned}
\mathrm{C} & =\text { blade chord } \\
\mathrm{C}_{x} & =\text { blade axial chord } \\
\mathrm{V} & =\text { velocity } \\
\mathrm{P} & =\text { static pressure } \\
\dot{\mathrm{m}}_{\mathrm{c}} & =\text { mass flow rate of coolant } \\
\dot{\mathrm{m}}_{1} & =\text { mass flow rate of inlet of cascade } \\
\dot{\mathrm{m}}_{\infty} & =\text { mass flow rate of mainstream } \\
\rho & =\text { density }
\end{aligned}
$$

$$
\begin{aligned}
& \mathrm{P}_{0}=\text { stagnation pressure } \\
& \mathrm{TE}=\text { trailing edge } \\
& \mathrm{LE}=\text { leading edge } \\
& \mathrm{P}_{01, \text { ref }}=\text { referenced inlet stagnation pressure, } \\
& \left(\dot{\mathrm{m}}_{\mathrm{c}} * \mathrm{P}_{01}+\dot{\mathrm{m}}_{\infty} * \mathrm{P}_{0 \mathrm{c}}\right) /\left(\dot{\mathrm{m}}_{\mathrm{c}}+\dot{\mathrm{m}}_{\infty}\right) \\
& \mathrm{C}_{\mathrm{p} 0}=\text { total (stagnation) pressure loss coefficient, } \\
& \left(\mathrm{P}_{01}-\mathrm{P}_{0}\right) /\left(\mathrm{P}_{01}-\mathrm{P}_{2}\right) \\
& \mathrm{C}_{\mathrm{p}}=\text { static pressure coefficient, } \\
& \left(\mathrm{P}_{01}-\mathrm{P}\right) /\left(\mathrm{P}_{01}-\mathrm{P}_{2}\right) \\
& \mathrm{s}=\text { wetted length } \\
& \mathrm{TLF}=\text { tip leakage flow } \\
& \mathrm{TLV}=\text { tip leakage vortex } \\
& \mathrm{PV}=\text { passage vortex } \\
& \mathrm{Y}_{\mathrm{p}, \text { tot }}=\text { mixed-out loss } \\
& \mathrm{Y}_{\mathrm{p}, \text { prof }}=\text { mixed-out loss caused by blade profile } \\
& \mathrm{Y}_{\mathrm{p}, \mathrm{TLV}}=\text { mixed-out loss caused by TLV, } \\
& Y_{p, t o t}-Y_{p, p r o f} \\
& \omega_{\mathrm{s}}^{*}=\text { dimensionless streamwise vorticity } \\
& \mathrm{T}_{\mathrm{w}}=\text { wall temperature } \\
& \mathrm{T}_{\mathrm{aw}}=\text { adiabatic wall temperature } \\
& \mathrm{q}=\text { heat flux } \\
& \mathrm{h}=\text { heat transfer coefficient } \\
& \mathrm{h}_{\mathrm{c}} / \mathrm{h}_{\mathrm{uc}}=\text { heat transfer coefficient increment } \\
& \eta=\begin{array}{l}
\text { cooling effectiveness, } \\
\left(\mathrm{T}_{\mathrm{aw}}-\mathrm{T}_{01}\right) /\left(\mathrm{T}_{0, \mathrm{c}}-\mathrm{T}_{01}\right)
\end{array} \\
& \text { NHFR }=\text { net heat flux reduction, }\left(\mathrm{q}_{\mathrm{uc}}-\mathrm{q}_{\mathrm{c}}\right) / \mathrm{q}_{\mathrm{uc}} \\
& \mathrm{Q}=\text { heat load, } \int_{\mathrm{A}} \mathrm{q}\left(\mathrm{T}_{01}-\mathrm{T}_{\mathrm{w}}\right) \mathrm{dA} \\
& \Theta_{\mathrm{E}}=\text { non-dimensional engine temperature } \\
& \Theta_{\mathrm{E}}=\left(\mathrm{T}_{01}-\mathrm{T}_{0, \mathrm{c}}\right) /\left(\mathrm{T}_{01}-\mathrm{T}_{\mathrm{w}}\right) \\
& \mathrm{BR}=\text { blowing ratio of coolant, }\left(\rho_{\mathrm{c}} \mathrm{v}_{\mathrm{c}}\right) /\left(\rho_{\infty} \mathrm{v}_{\infty}\right) \\
& \text { ITI }=\text { inlet turbulent intensity } \\
& \text { ETI }=\text { exit turbulent intensity }
\end{aligned}
$$

Subscripts

$0=$ stagnation condition 


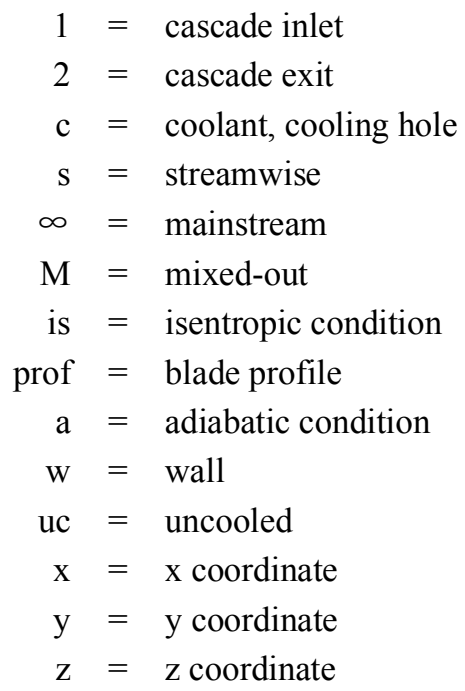

\section{INTRODUCTION}

In an unshroud high-pressure turbine, to prevent the rubbing between blade tip and casing, tip clearance generally exists in most rotors. Due to the pressure difference between the suction side and the pressure side of blade, the fluid flows through the clearance and develops into tip leakage flow (TLF). When tip leakage flow leaves blade tip clearance to the passage of blade, tip leakage vortex (TLV) becomes strong progressively. Shown as Figure 1, the TLV becomes intensified gradually in a typical highly-loaded high-pressure turbine. Because of the existence of TLV, aerodynamic loss is increased in turbine. This causes that the efficiency of turbine drops significantly.

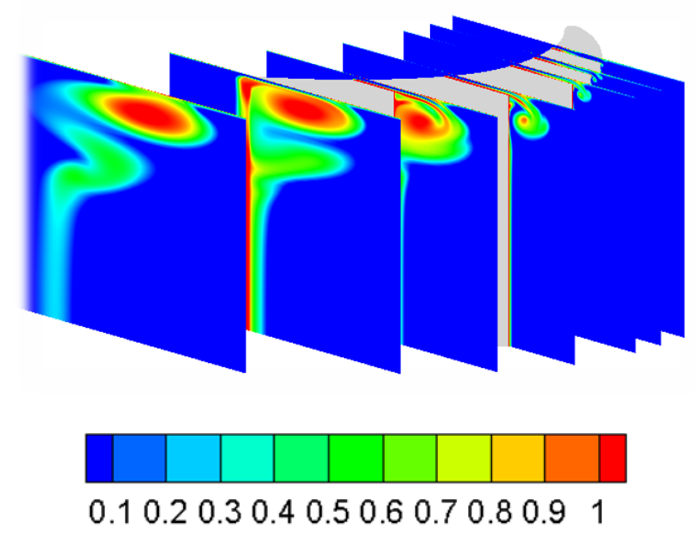

\section{Figure 1 Stagnation Pressure Loss Coefficient $\left(C_{p 0}\right)$ Distribution}

The challenges of designing turbine blade derive from not only aerodynamic aspect but also heat transfer problem of blade surface. Improving the inlet temperature of highpressure turbine can promote engine heat cycle efficiency and output power. With the development of technique of aeroengine, model turbine inlet temperature has been far more than the limitation of metal material of turbine blade. Working in this condition, the materials of turbine blade may generate metal fatigue, creep deformation and even fusion. The accelerated high temperature gas in tip gap by pressure difference between two sides of blade intensifies the thermal erosion of blade tip structure, as well as blade surface. As shown in Figure 2, after the blade of high-pressure turbine working over a period of time in a real engine, it is obvious to identify the trace of thermal erosion on the suction and pressure surface. And much more severely, there is loss of materials on the blade tip along the suction side. This causes the increasing of mass flow rate of TLF and corresponding loss. For such reasons, the study of heat transfer problem of turbine blade becomes more and more significant.
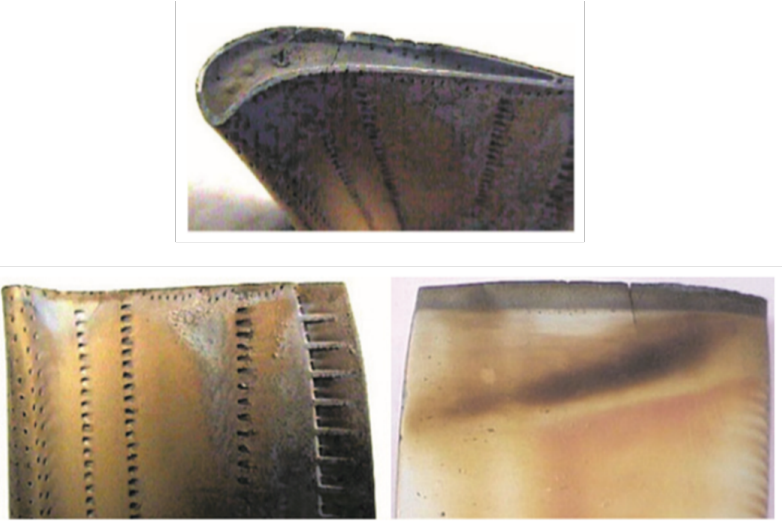

Figure 2 Thermal Erosion [1]

To control the harm of TLV, many methods have been used in the past decades, such as decreasing the tip gap between blade and casing, changing the geometry of blade tip and so on. One of these methods is to eject the coolant from the blade surface and tip.

Hohlfeld et al [2] and Couch et al [3] studied the impact of different sizes of tip gap on the effect of coolant released from dirt purge holes of a flat tip blade in a turbine cascade. The influence of different blowing ratios (BRs) of coolant was also investigated. The main focus of their paper was on the thermal performance of coolant, but the aerodynamic performance was not discussed a lot.

Zhou et al. [4] studied the mechanism of tip coolant ejection in detail. First of all, they investigated the aerodynamic effects of tip cooling. And then they studied the different performances of two cooled flat tips, a cooled suction side squealer tip and a cooled cavity tip. Finally, they investigated the effects of different mass flow rates of coolant and different sizes of tip gap.

Volino. [5] studied influence of many factors, such as jet locations, size, inclination angle, and velocity, on the total pressure drop through the blade row with flat tip and squealer tip blades respectively. Condition without tip blowing was set as baseline case.

Krishnababu et al. [6] studied flow and heat transfer characteristics of tip leakage flow in a typical rotor with three different modifications to a standard blade tip. Several indexes, such as tip gap exit mass flow, total area of the tip 
affected by the hot flow, and the total heat flux to the tip, were used to evaluate the performance of modified geometries.

Kwak et al. [7] investigated the thermal performance of a flat tip blade and a squealer tip blade with two kinds of methods to release coolant. One method was to release coolant from blade tip only, and the other was from blade tip and pressure surface of blade. The results showed that the latter method could achieve better thermal performance of turbine blade, with the consideration of heat transfer coefficient and film cooling effectiveness distributions.

Rezasoltani et al. [8] also investigated film cooling effectiveness of a plane tip and a squealer tip with coolant released from blade tip and blade pressure side respectively in a high-pressure turbine under rotation condition. The different blowing ratios of coolant and different rotational speeds were also investigated.

Newton et al. [9] came up with an effective method to cool the tip of a generic turbine blade. The method was instructed by the contours of heat transfer coefficient of an uncooled blade tip and necessary experience of fluid dynamics about the flow between casing and blade tip.

After the work of Newton et al. [9], Zhou et al. [10] expanded the study of aerothermal performance of turbine by applying more cooled-tip geometries. The aerothermal performance of two kinds of cooled flat tip, a cooled suctionside squealer tip and a cooled cavity tip were studied by CFD method with a tip gap of $1.6 \%$ chord $(\mathrm{C})$ of blade. By applying the parameters of cooling effectiveness $(\eta)$, heat-transfer coefficient (h), net heat flux reduction (NHFR), heat-transfer rate $(\mathrm{q})$ and heat load $(\mathrm{Q})$, they provided detailed information of aerothermal performance of cooled tips and discussed the mechanism of cooling with different cooled-tip geometries. What's more, the effects of mass flow ratio of coolant and endwall motion on the aerothermal performance of turbine were also investigated.

Tamunobere et al. [11] studied tip cooling using holes at the tip and pressure side of blade with different blowing ratios under blade rotating condition. The extent of BR was from 1.0 to 4.0 and uncooled case was set as baseline. Reynolds number based on the blade axial chord $\left(\mathrm{C}_{x}\right)$ and the rotor inlet absolute velocity in test was 140,000 .

Christophel et al. [12] studied cooling holes located at the pressure side of blade. Different tip gaps and coolant flow rates were investigated. The adiabatic effectiveness along the turbine blade tip was used to present the different results. Christophel et al. [13] evaluated the overall benefit of tip cooling.

Gao et al. [14] investigated the impact of different incidence angels on tip film cooling of blade for squealer blade tip with cutbacks. The study was conducted under conditions of relatively high pressure-ratio and freestream Mach number at three mainstream inlet angels, 0 degree (design condition) and \pm 5 degree (off-design conditions).

Arisi et al. [15] studied the effect of Mach/Reynolds number on heat transfer coefficient and film cooling effectiveness for a blade of squealer tip. The impact of ribs in squealer cavity were also studied.
Naik et al. [16] investigated the effect of two different blade squealer tip geometries on the aerothermal performance of turbine cascade. The dust holes were in the tip cavity and film cooling holes were along the pressure side of blade. The experimental and numerical methods have been conducted.

Lots of studies were concerned with the performance of coolant released from blade tip or/and pressure surface. However, relatively fewer publications about coolant released from suction surface could be found. The work of this paper was to study the influence of coolant released from suction surface on the aerodynamic and thermal performance of a high-pressure turbine cascade. The results of simulations could be divided into two parts: the first part was to study the impact of different axial positions of blade to release coolant on the control of TLV and relevant turbine performance and to obtain an optimal strategy to release coolant; the second part was to investigate the impact of different blowing ratios on the control of TLV and relevant turbine performance at the optimal position to release coolant.

\section{METHODOLOGY}

The current study was conducted by numerical method. The computation was to simulate the condition of the large-scale low-speed turbine cascade in Turbomachinery Laboratory of Peking University. Figure 3 shows the layout of the large-scale low-speed turbine cascade used to conduct experiments to validate the result of CFD. The profile of blade was redesigned from a typical highly-load high-pressure turbine blade. Many basic studies and experiments have been conducted on this kind of blade (Zhong and Zhou [17], Zhou and Zhou [18]).

The parameters of simulated blade and cooling hole are shown in Table 1. The chord of blade is $292 \mathrm{~mm}$ and the axial chord is $220 \mathrm{~mm}$. The tip gap of blade is $2.26 \% \mathrm{C}_{x}$. The diameter of cooling hole is $1.8 \% \mathrm{C}_{x}$, which refers to Zhou et al. [10]. And the axial positions of cooling hole on suction surface are $10 \%, 20 \%, 30 \%, 40 \%$ and $50 \% \mathrm{C}_{x}$ of blade respectively. The five choices of cooling hole locate at the positions of different stages of TLV. Figure 4 shows the coolant released angle. The red arrow represents the coolant. PS and SS represent pressure side and suction side of blade respectively. The angel between coolant and blade surface normal vector is 60 degrees. And the initial direction of coolant is perpendicular to flow direction.

The structured grid was generated in ANSYS ICEMCFD and the number of hexahedral mesh is about 8 million. The maximum growth factor of the grid is less than 1.2. O-block topology was used around the blade and the cooling holes to improve the quality of mesh at these areas. The overall view of the leading edge (LE) of the blade and the cooling holes is shown in Figure 5.

The simulation was run in commercial software ANSYS FLUENT to solve the steady Reynolds-averaged NavierStokes (RANS) equations. The spatial discretization of these equations was second order accuracy. The solution method 
was set as SIMPLEC pressure-velocity coupling. The turbulent model used in simulation was k-omega shear stress transport (SST). The area-averaged y plus on the blade tip is less than 1.3. The inlet of the computational domain was located at $47.6 \%$ axial chord upstream of blade leading edge. The "hub" was set as symmetry type to simulate high aspect ratio condition. To decrease the cost of computation, the periodic condition was used to simulate a row of blades.

The simulated condition is in Table 2. The Reynolds number based on the axial chord of blade and exit isentropic velocity was about $3.1 \times 10^{5}$. To simulate the non-dimensional engine temperature $\left(\Theta_{E}\right)$ in real condition, the inlet temperature of turbine cascade $\left(\mathrm{T}_{01}\right)$, the temperature of blade surface $\left(\mathrm{T}_{\mathrm{w}}\right)$ and the temperature of coolant $\left(\mathrm{T}_{0, \mathrm{c}}\right)$ were shown below.

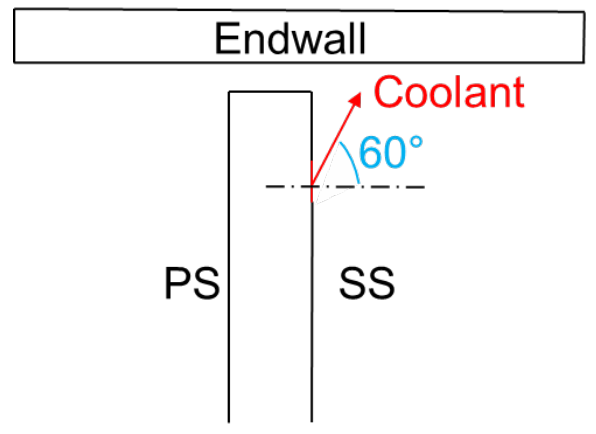

Figure 4 Coolant Released Angle Sketch

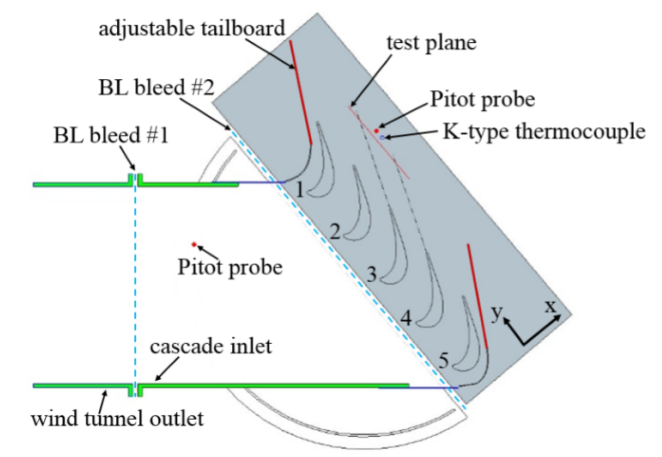

Figure 3 Layout of the Cascade [17]

\section{Table 1 Parameters of Blade and Cooling Hole}

\begin{tabular}{lr}
\hline $\mathrm{C}$ & $292 \mathrm{~mm}$ \\
$\mathrm{C}_{x}$ & $220 \mathrm{~mm}$ \\
Span & $113.64 \% \mathrm{C}_{x}$ \\
Pitch & $104.55 \% \mathrm{C}_{x}$ \\
Tip Gap & $2.26 \% \mathrm{C}_{x}$ \\
Inlet Metal Angel & $41.1^{\circ}$ \\
Exit Metal Angel & $-69.3^{\circ}$ \\
Diameter of Cooling Hole & $1.8 \% \mathrm{C}_{\mathrm{x}}$ \\
Distance between Tip and Cooling Hole & $5.68 \% \mathrm{C}_{\mathrm{x}}$ \\
Axial Positions of Cooling Hole & $10 \%-50 \% \mathrm{C}_{\mathrm{x}}$ \\
\hline
\end{tabular}

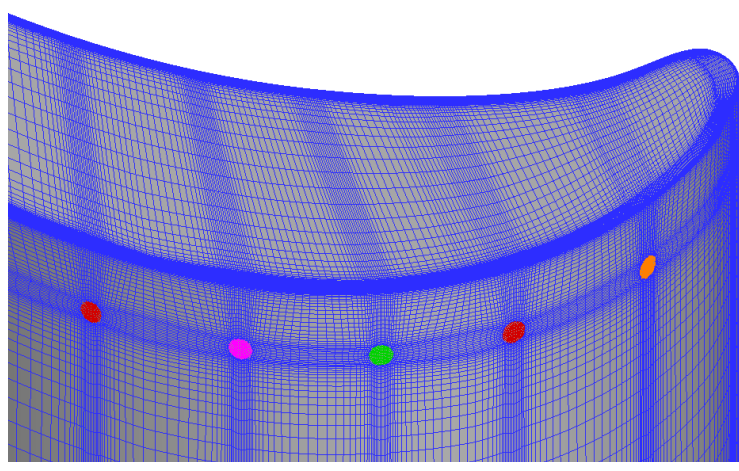

Figure 5 Mesh of Blade and Cooling Holes

\begin{tabular}{lr}
\multicolumn{2}{c}{ Table 2 working conditions } \\
\hline $\mathrm{V}_{2, \text { is }}$ & $21.9 \mathrm{~m} / \mathrm{s}$ \\
$\operatorname{Re}\left(\mathrm{C}_{\mathrm{x}}, \mathrm{V}_{2, \text { is }}\right)$ & $3.1 \times 10^{5}$ \\
$\mathrm{~T}_{01}$ & $300 \mathrm{~K}$ \\
$\mathrm{~T}_{\mathrm{w}}$ & $280 \mathrm{~K}$ \\
$\mathrm{~T}_{0, \mathrm{c}}$ & $270 \mathrm{~K}$ \\
$\Theta_{\mathrm{E}}$ & 1.5 \\
$\mathrm{ITI}$ & $0.8 \%$ \\
$\mathrm{ETI}$ & $2 \%$ \\
$\mathrm{TI}_{\mathrm{c}}$ & $1 \%$ \\
$\mathrm{BR}$ & $0.7-2.1$ \\
\hline
\end{tabular}




\section{VALIDATIONS}

The grid dependency study was conducted by three kinds of meshes, namely 3, 6.5 and 14.5 million nodes respectively. The method to check gird dependency was adopted to the calculation principle in the paper of Roache [19]. The result is showed in Table 3. From the tendency of $\mathrm{y}^{+}$and relative deviation of $Y_{p, T L V}$, it can be concluded that the impact of mesh number can be neglected when the number of mesh nodes is more than 6.5 million.

Figure 6 shows static pressure coefficient $\left(C_{p}\right)$ distribution at the midspan of blade. The red crosses represent the datum from experiment and the black lines represent the result of CFD. It is obvious that the result of CFD agrees well with experiment.

Figure 7 shows stagnation pressure loss coefficient $\left(C_{p 0}\right)$ distribution on the plane of $30 \% \mathrm{C}_{x}$ downstream of trailing edge (TE). Figure 7 (a) shows the result of experiment and (b) shows the result of CFD. The blank zone near end wall of experiment was due to the limitation of measurement tools. From Figure 7, it can be concluded that the distribution of TLV, passage vortex (PV) and wake in simulation matches well with the result of experiment as a whole.

As for the credibility of heat transfer of turbulent model (komega SST) in simulation, many studies have provided the validation (Naik et al. [16] and Zhang et al. [20]).

Table 3 Grid Dependency Study

\begin{tabular}{|c|c|c|c|c|}
\hline & $\begin{array}{c}\text { Mesh } \\
\text { Nodes } \\
\left(\mathrm{x} 10^{6}\right)\end{array}$ & $\begin{array}{c}\text { Tip } \\
\text { Averaged } \\
\mathrm{y}^{+}\end{array}$ & $\mathrm{Y}_{\mathrm{p}, \mathrm{TLV}}$ & $\begin{array}{c}\text { Relative } \\
\text { Deviation }\end{array}$ \\
\hline Grid1 & 3 & 1.808 & 0.095 & $3.00 \%$ \\
\hline Grid2 & 6.5 & 1.396 & 0.0967 & $1.20 \%$ \\
\hline Grid3 & 14.5 & 1.066 & 0.0974 & $0.50 \%$ \\
\hline Extrapolation & - & - & 0.0979 & - \\
\hline
\end{tabular}

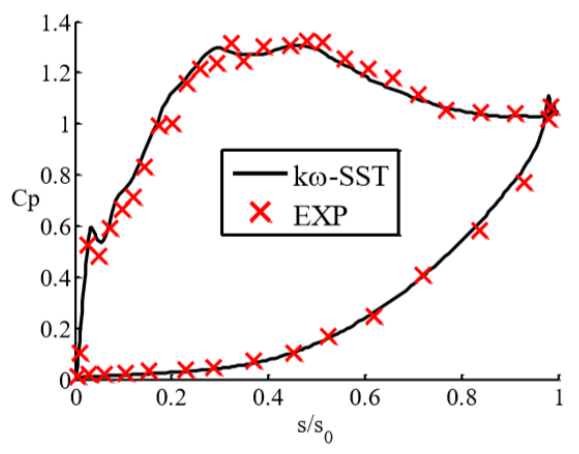

Figure 6 Static Pressure Coefficient $\left(C_{p}\right)$ Distribution at Midspan of Blade [18]

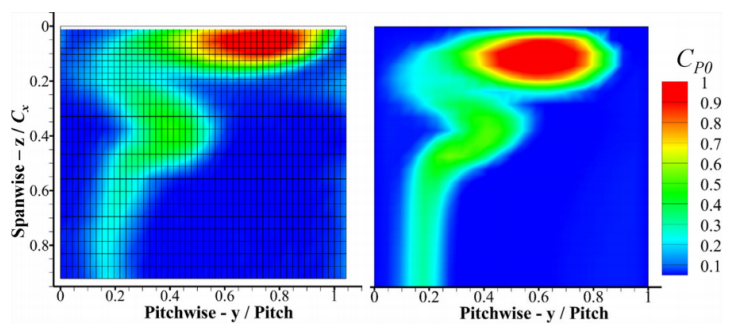

(a) EXP

(b) CFD

Figure 7 Stagnation Pressure Loss Coefficient $\left(C_{p 0}\right)$ Distribution of $30 \% \mathrm{C}_{x}$ Downstream of TE [18]

\section{DEFINITION OF IMPORTANT PARAMETERS}

Shown in Figure 8, plane 1 (inlet), plane 2 (exit) and plane 3 (M) represent the inlet plane of cascade, the calculated plane and the plane where parameters have been mixed-out respectively. For the calculated plane, the mixed-out loss caused by TLV ( $\left.\mathrm{Y}_{\mathrm{p}, \mathrm{TLV}}\right)$ can be calculated by the equations from (1) to (3).

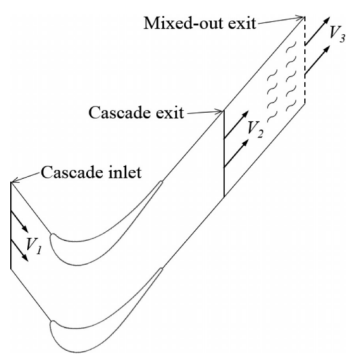

Figure 8 Mixed-Out Loss Calculation Sketch [17]

$$
\begin{gathered}
Y_{p, t o t}=1-\left(\frac{V_{M}}{V_{i s}}\right)^{2} \\
Y_{p, p r o f}=1-\left(\frac{V_{M, p r o f}}{V_{\text {is,prof }}}\right)^{2} \\
Y_{p, T L V}=Y_{p, t o t}-Y_{p, p r o f}
\end{gathered}
$$

The release of coolant from the suction surface of blade equals to add energy to the domain of simulation. So, the reference stagnation pressure used to calculate stagnation pressure loss coefficient should be calculated by the equation (4). And the corresponding stagnation pressure loss coefficient should be calculated by the equation (5).

$$
\begin{aligned}
P_{01, r e f} & =\frac{\dot{m}_{1} P_{01}+\dot{m}_{c} P_{0 c}}{\dot{m}_{1}+\dot{m}_{c}} \\
C_{p 0} & =\frac{P_{01, r e f}-P_{0}}{P_{01, r e f}-P_{2}}(5)
\end{aligned}
$$


The definition of dimensionless streamwise vorticity is shown below.

$$
\begin{gathered}
\omega_{s}=\frac{\omega_{x} V_{x}+\omega_{y} V_{y}+\omega_{z} V_{z}}{\sqrt{V_{x}^{2}+V_{y}^{2}+V_{z}^{2}}}(6) \\
\omega_{s}^{*}=\frac{\omega_{s} C_{x}}{V_{2, i s}}(7)
\end{gathered}
$$

\section{RESULTS AND DISCUSSIONS}

The mixed-out loss caused by TLV is presented in Figure 9, where the red line presents the base case without coolant. And the blue line represents the cases with coolant released from different axial positions on the suction surface of blade. The plane used to calculate mixed-out loss is $30 \% \mathrm{C}_{x}$ downstream of blade trailing edge. The numbers from 1 to 5 represent the five positions, namely from $10 \%$ to $50 \% \mathrm{C}_{x}$ of blade, to release coolant respectively. From Figure 9, it is obvious that the mixed-out loss caused by TLV increases with the position to release coolant away from LE of blade on the whole. And after position 4, the mixed-out loss in the case with coolant exceeds the base case without coolant.

Because the cases of releasing coolant from $10 \%$ and $20 \%$ $\mathrm{C}_{x}$ of blade are similar and the cases of $40 \%$ and $50 \% \mathrm{C}_{x}$ of blade are similar, Figure 10 only shows the two typical cases with coolant from $20 \% \mathrm{C}_{x}$ and $40 \% \mathrm{C}_{x}$ of the blade. The red lines represent TLF and the black lines represent coolant. The mixing process of TLV and coolant released from $20 \% \mathrm{C}_{\mathrm{x}}$ of blade and that of $40 \%$ are different. The coolant released from $20 \% \mathrm{C}_{\mathrm{x}}$ of blade mixes with TLF when the TLV does not form obviously, but the coolant released from $40 \% \mathrm{C}_{\mathrm{x}}$ of blade is mixed with TLV when the TLV forms obviously.

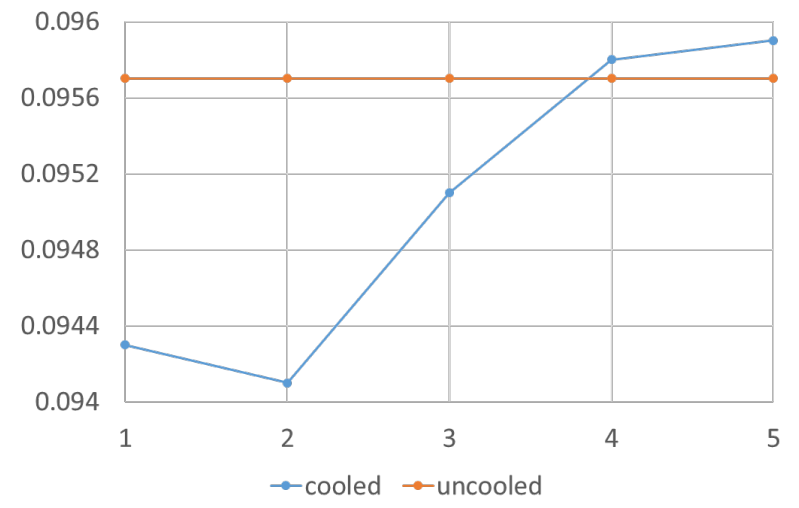

Figure 9 Mixed-Out Loss Caused by TLV (Y,TLV) of $30 \% \mathrm{C}_{x}$ Downstream of TE with Different Positions to Releasing Coolant
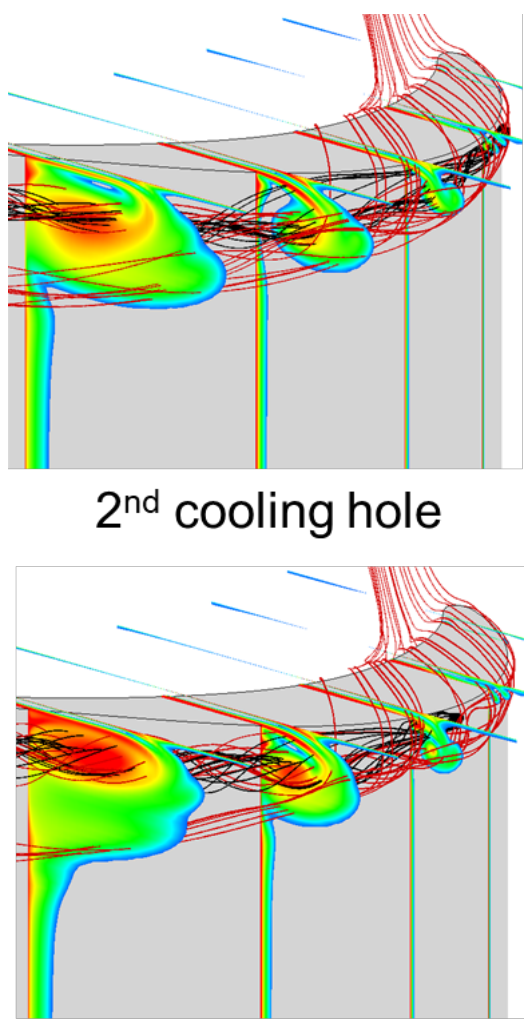

$4^{\text {th }}$ cooling hole

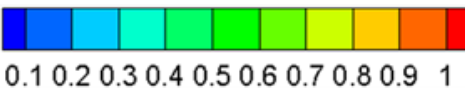

\section{Figure 10 Stagnation Pressure Loss Coefficient $\left(C_{p_{0}}\right)$ Distribution with Coolant Released from Different Positions}

Figure 11 shows the evolution of streamwise vorticity distribution in the blade passage. Figure 11 (a) shows the base case without coolant and this case is set as a contrast. And Figure 11 (b) and Figure 11 (c) show the cases with the coolant released from $20 \%$ and $40 \%$ axial chord of blade respectively. In Figure 11, the blue region represents TLV and the red region represents PV derived from the boundary layer of casing end wall. The enlarged drawings of circled regions at $30 \%, 40 \%$ and $50 \% \mathrm{C}_{x}$ of blade in the Figure 11 (a) show the evolution of early stage of TLV. It is generally considered that the TLV is formed and strong enough at the axial position of $40 \%$ axial chord of blade. In Figure 11 (b), coolant released from $20 \% \mathrm{C}_{x}$ of blade mixes with TLF when TLV is not strong. Due to the mixing process of coolant and TLF, the intensity of TLV weakens, which is presented by the dimensionless streamwise vorticity of TLV. From the dimensionless streamwise vorticity distribution of TLV, it is obvious that the evolution of TLV also changes. The position of TLV is farther away from suction surface of blade under the inducement of PV. This inducement is not significant in the 
base case without coolant. However, when the intensity of TLV is weakened due to mixing process with coolant, the effect of inducement of PV becomes significant. But the situation of coolant released from $40 \%$ axial chord of blade is not desired, because the TLV is gradually formed at $40 \%$ axial chord of blade. The intensity of TLV becomes strong enough to resist the control from mixing process, so the effect of coolant is not noteworthy. As a result, the evolution of TLV is similar with the base case without coolant.

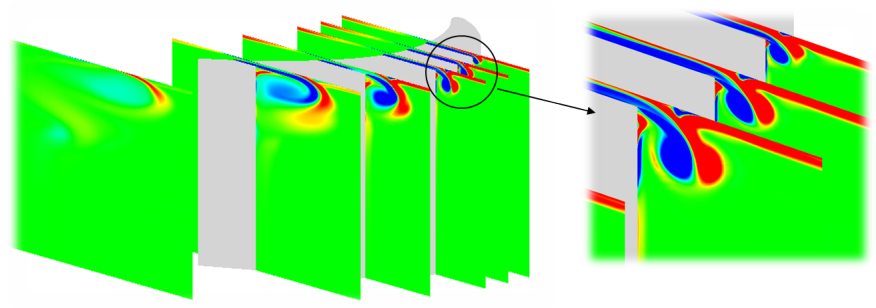

(a) uncooled

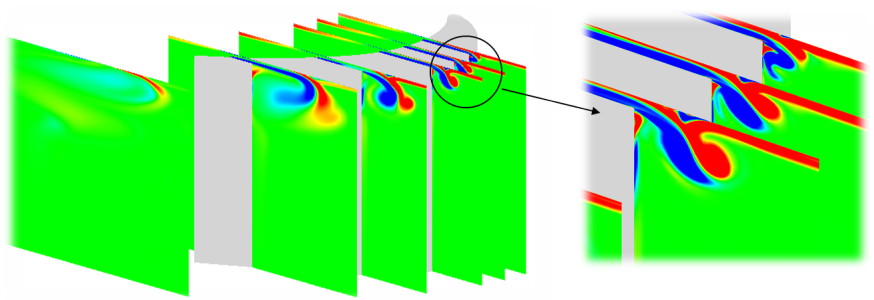

(b) coolant from $2^{\text {nd }}$ cooling hole

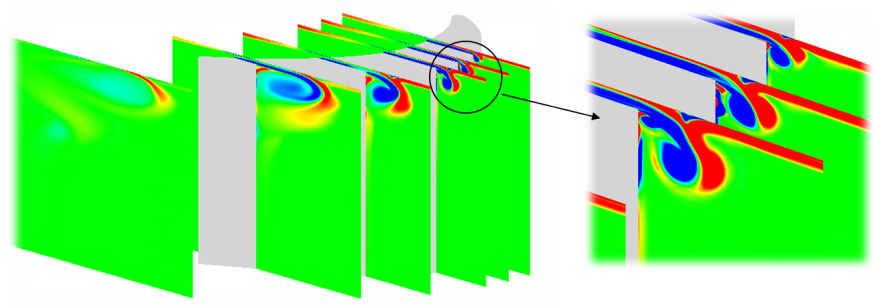

(c) coolant from $4^{\text {th }}$ cooling hole

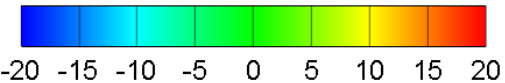

Figure 11 Dimensionless Streamwise Vorticity $\left(\omega_{\mathrm{s}}^{*}\right)$ Distribution with Different Positions to Releasing Coolant

Figure 12 shows the evolution of stagnation pressure loss coefficient distribution in turbine blade passage, which is regarded as the reference of aerodynamic performance in current paper. Figure 12 (a) shows the base case without coolant. Figure 12 (b) and Figure 12 (c) show the cases with coolant released from $20 \%$ and $40 \%$ axial chord of blade respectively. From Figure 12, it is obvious that the position of releasing coolant is very significant to the effect of coolant. The coolant released before the location where TLV is formed obviously weakens the intensity of TLV and the corresponding loss decreases in contrast to base case without coolant. However, once the coolant is released after the position where the TLV is formed obviously, the effect of coolant on the aerodynamic performance is not obvious and even causes loss to increase.

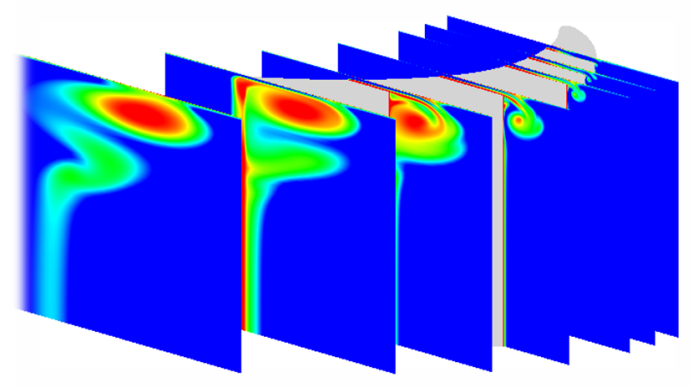

(a) uncooled

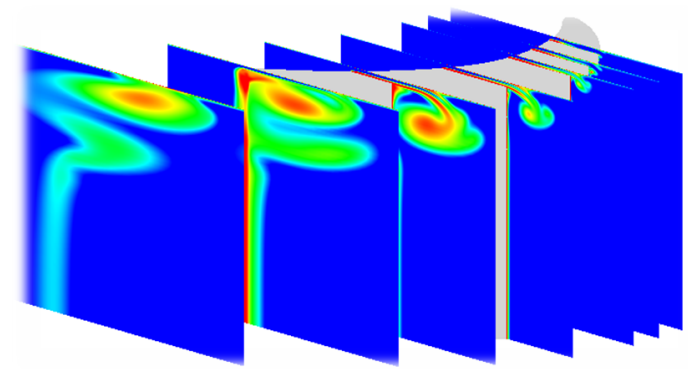

(b) coolant from $2^{\text {nd }}$ cooling hole

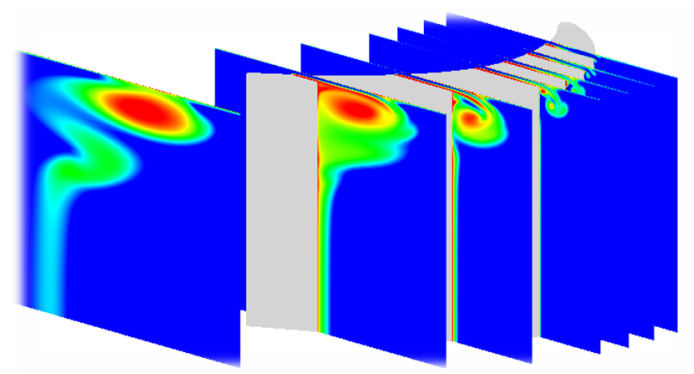

(c) coolant from $4^{\text {th }}$ cooling hole

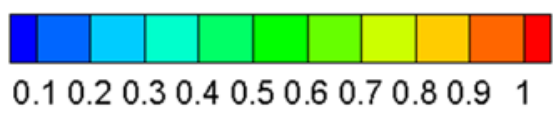

\section{Figure 12 Stagnation Pressure Loss Coefficient $\left(C_{p 0}\right)$ Distribution with Different Positions to Releasing Coolant}

From the discussion above, it can be concluded that the coolant should be released before where TLV becomes strong. Furthermore, the aero-thermal performance of the coolant is also discussed in the later with different blowing ratios of coolant released from $20 \%$ axial chord of blade. Figure 13 shows the evolution of dimensionless streamwise vorticity distribution in the blade passage with different blowing ratios from 0.7 to 2.1. From Figure 13, it can be found that the intensity of dimensionless streamwise vorticity of TLV 
becomes weakened gradually with the blowing ratio increasing. This is because the control from mixing process of coolant and TLF on the intensity of TLV becomes progressively significant with the increasing of coolant mass flow rate. With the reduction of intensity of TLV, the inducement of PV on TLV becomes progressively significant. As a result, the position of TLV is farther away from suction surface of blade.

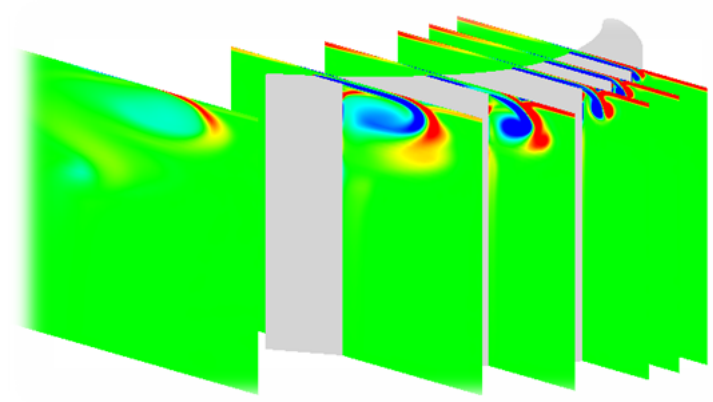

(a) $\mathrm{BR}=0.7$

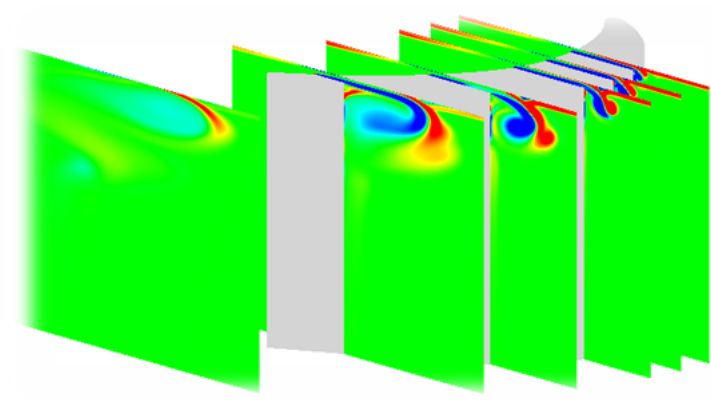

(b) $\mathrm{BR}=1.4$

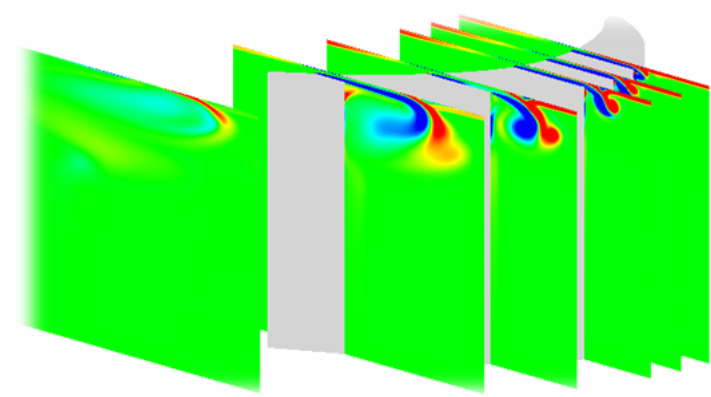

(c) $\mathrm{BR}=2.1$

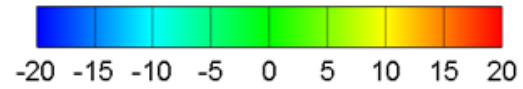

Figure 13 Dimensionless Streamwise Vorticity $\left(\omega_{\mathrm{s}}^{*}\right)$ Distribution with Different Blowing Ratios

Figure 14 shows the evolution of stagnation pressure loss coefficient distribution in blade passage with different blowing ratios from 0.7 to 2.1 . From the plane at $30 \%$ axial chord downstream of blade TE in the Figure 14 (a), (b) and (c), it is obvious that the stagnation pressure loss coefficient is reduced successively with the increasing of blowing ratio.

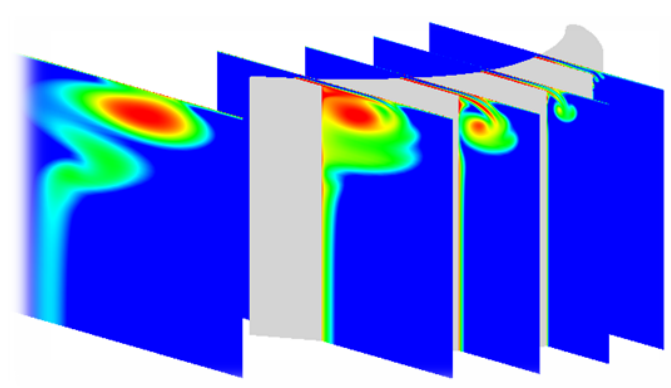

(a) $\mathrm{BR}=0.7$

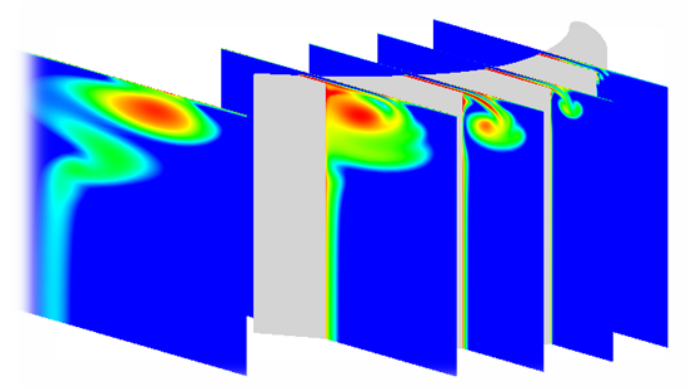

(b) $\mathrm{BR}=1.4$

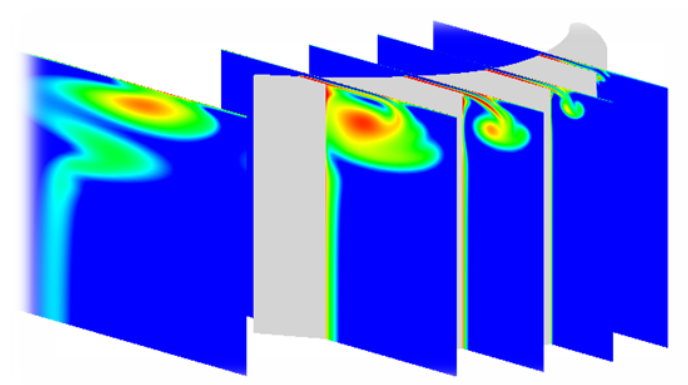

(c) $\mathrm{BR}=2.1$

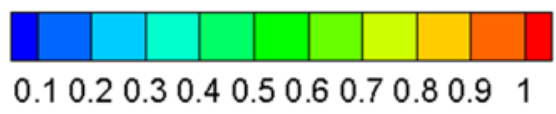

\section{Figure 14 Stagnation Pressure Loss Coefficient $\left(C_{p 0}\right)$ Distribution with Different Blowing Ratios}

Figure 15 presents that the mixed-out loss caused by TLV of the plane at $30 \% \mathrm{C}_{x}$ downstream of $\mathrm{TE}$ with different blowing ratios. The red bar represents the base case without coolant and the green bars represent the cases with coolant released from $20 \% \mathrm{C}_{x}$ of blade with different BRs. The calculation result shows that the coolant reduces mixed-out loss caused by TLV and the effect becomes progressively significant with the increasing of blowing ratio of coolant. This interesting result implies that by discreetly controlling the blowing ratio of coolant, the tip leakage loss can be eliminated compared to the uncooled case. The discussion above is about the aerodynamic performance in turbines, and the following begins to discuss about the thermal performance of turbine blade surface. The cooling effectiveness, heat transfer coefficient, NHFR and heat load are used to present the results 
of cases with different BRs of coolant and help to analyse the thermal performance of turbine blade surface.

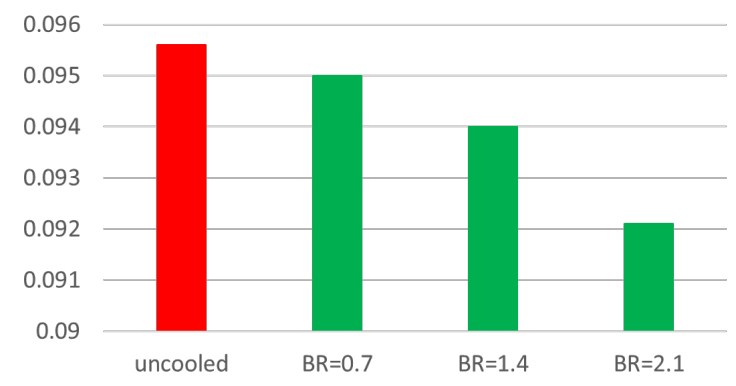

Figure 15 Mixed-Out Loss Caused by TLV ( $\left.\mathrm{Y}_{\mathrm{p}, \mathrm{TLV}}\right)$ of the Plane of $30 \% \mathrm{C}_{x}$ Downstream of TE with Different Blowing Ratios

Figure 16 shows cooling effectiveness of upper part of suction surface with different blowing ratios. The span expansion of blade presented in Figure 16 is only $22.6 \% \mathrm{C}_{x}$, because the larger extent of blade is not impacted by coolant. From Figure 16, it is obvious that the cooling effectiveness becomes better with the blowing ratio decreasing. This phenomenon can be explained as the coolant is carried away from blade surface with the blowing ratio increasing. What's more, the coolant mainly affects the region near the cooling hole and the effect attenuates quickly downstream of cooling hole.

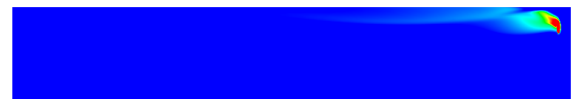

(a) $\mathrm{BR}=0.7$

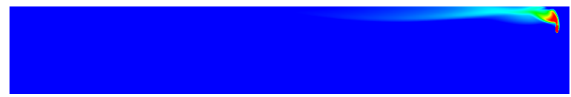

(b) $\mathrm{BR}=1.4$

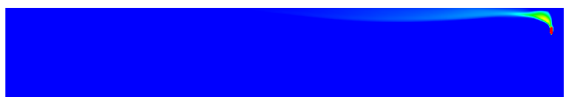

(c) $\mathrm{BR}=2.1$

$\begin{array}{lllllllll}0.1 & 0.2 & 0.3 & 0.4 & 0.5 & 0.6 & 0.7 & 0.8 & 0.9\end{array}$

Figure 16 Cooling Effectiveness $(\eta)$ of $22.6 \% C_{x}$ Spanwise of Suction Surface with Different Blowing Ratios

From the distribution of cooling effectiveness, the effect of coolant is confined to the region near the cooling hole, but the heat transfer coefficient increment in Figure 17 shows something different. The $h_{c}$ represents the heat transfer coefficient of blade suction surface in the case of coolant released from $20 \% \mathrm{C}_{x}$ of blade and $\mathrm{h}_{\mathrm{uc}}$ represents that of base case without coolant. From Figure 17, the effect of coolant mainly impacts two areas of suction surface. One is the region near the tip from the cooling hole to about $60 \% \mathrm{C}_{x}$ of blade, named area1. The other is the region from about $50 \%$ axial chord of blade to trailing edge of blade under the area1, named area2. The area1 is protected by coolant, which flows past and covers area1. The situation of area 2 is a little more complex, because it is concerned with the evolution of TLV in the blade passage.

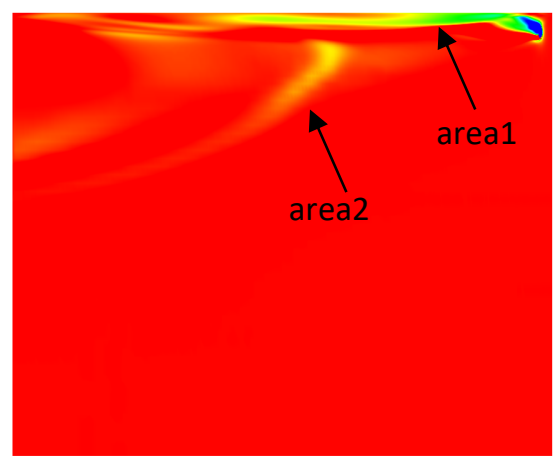

(a) $\mathrm{BR}=0.7$

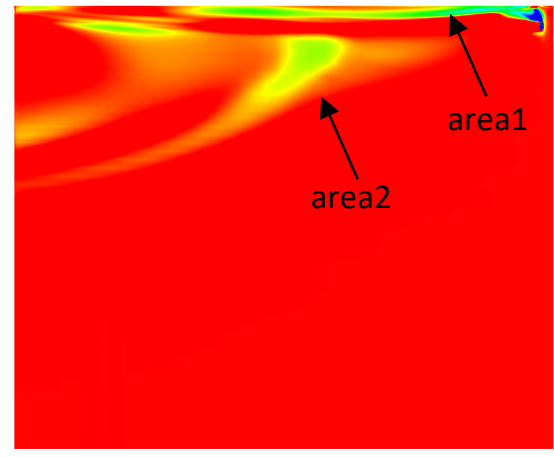

(b) $\mathrm{BR}=1.4$

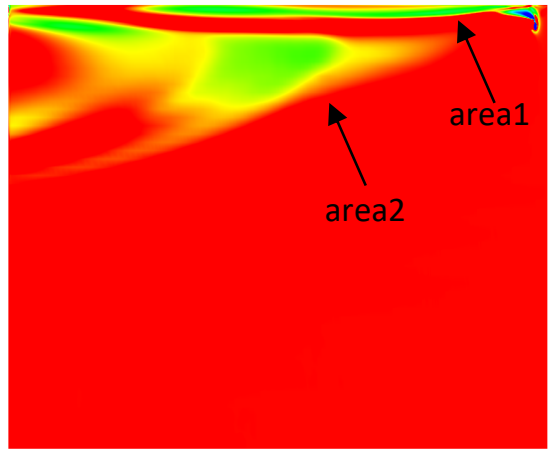

(c) $\mathrm{BR}=2.1$

$\begin{array}{lllllllllll}0 & 0.1 & 0.2 & 0.3 & 0.4 & 0.5 & 0.6 & 0.7 & 0.8 & 0.9 & 1\end{array}$

Figure 17 Heat Transfer Coefficient Increment $\left(h_{c} / h_{u c}\right)$ of Suction Surface with Different Blowing Ratios 
From the discussion about aerodynamic performance of turbine above, the intensity of TLV becomes weakened and the position of TLV is far away from suction surface with the increasing of blowing ratio of coolant. So, the interaction of TLV and suction surface is weakened. As a result, the heat transfer coefficient increment becomes better in the area 2 with the increasing of blowing ratio.

Figure 18 shows NHFR of suction surface with different blowing ratios of coolant. The tendency of NHFR is mainly similar with heat transfer coefficient increment. NHFR of suction surface is better with the increasing of blowing ratio.

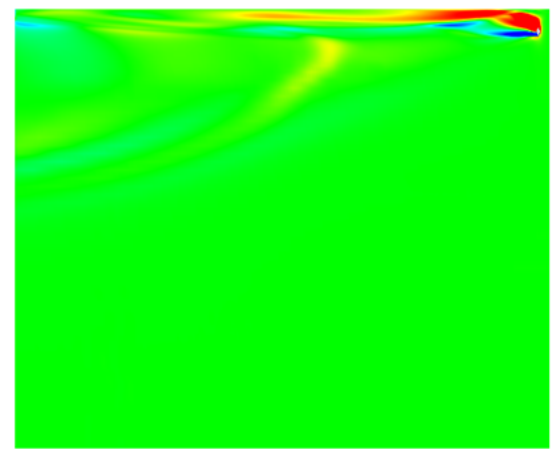

(a) $\mathrm{BR}=0.7$

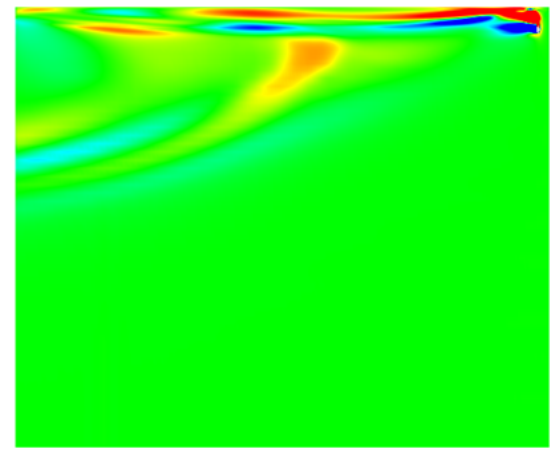

(b) $\mathrm{BR}=1.4$

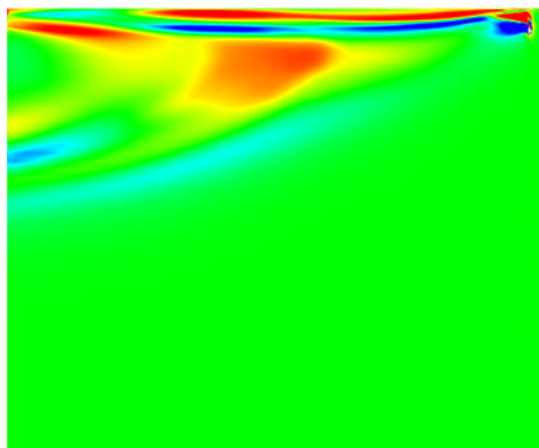

(c) $\mathrm{BR}=2.1$

$\begin{array}{lllllllllll}-0.5 & -0.4 & -0.3 & -0.2 & -0.1 & 0 & 0.1 & 0.2 & 0.3 & 0.4 & 0.5\end{array}$

Figure 18 NHFR of Suction Surface with Different Blowing Ratios
Figure 19 shows the normalized heat load of $59.1 \% \mathrm{C}_{x}$ spanwise of suction surface with different blowing ratios of coolant. The extent beyond $59.1 \% \mathrm{C}_{x}$ spanwise of suction surface is not impacted by TLV and coolant. The red bar represents uncooled condition and green bars represent conditions of different blowing ratios. The overall heat load of $59.1 \% \mathrm{C}_{x}$ spanwise of suction surface is reduced with the increasing of blowing ratio. The largest decrement of heat load is more than $6 \%$ compared with the base case without coolant, when the blowing ratio equals 2.1 .

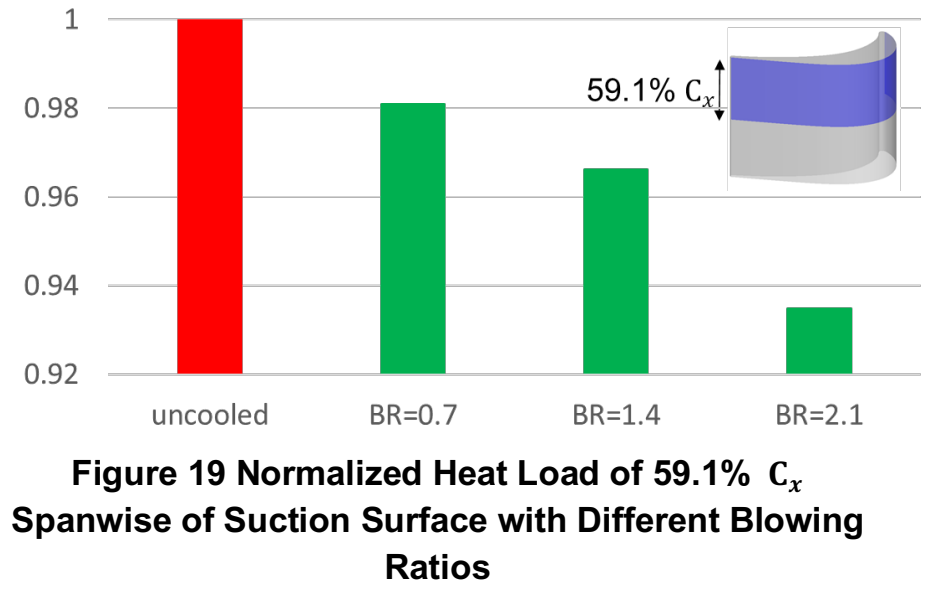

\section{CONCLUSIONS}

The aerodynamic and thermal performance of unshrouded high-pressure turbines were studied by computational fluid dynamics (CFD). The impact of different positions to release coolant from $10 \%$ to $50 \% \mathrm{C}_{x}$ on suction surface was considered. What's more, the influence of different blowing ratios of coolant, namely $0.7,1.4$, and 2.1, on the aero-thermal performance of unshrouded high-pressure turbines was also investigated by analysing the fluid physics and loss mechanisms.

The situations of coolant released from $20 \%$ and $40 \% \mathrm{C}_{x}$ of blade respectively were compared with the base case without coolant. The intensity of TLV was effectively controlled with coolant released from $20 \% \mathrm{C}_{x}$, which was not found with coolant released from $40 \% \mathrm{C}_{x}$. The reason was that the mixing processes of coolant and TLV in the two cases were different. Coolant released from $20 \% \mathrm{C}_{x}$ of blade was mixed with TLF when the TLV did not form obviously. The intensity of TLV was not strong at that place, so the effect of mixing process weakened the strength of TLV significantly and the formation of TLV was limited. As a result, the loss caused by TLV decreased. However, if the TLV was obviously formed, the injected coolant from $40 \% \mathrm{C}_{x}$ had little impact on the loss reduction. On the contrary, it even increased the mixing loss. The intensity of TLV at that place became strong enough to resist the effect of mixing process. In other words, the effect of mixing process on controlling TLV was not obvious and the formation of TLV was not be 
controlled. So, the existence of coolant only caused additional mixing loss.

When the coolant was released from $20 \%$ axial chord of blade, the effect of coolant on aerodynamic and thermal performance of turbine closely depended on the blowing ratio of coolant. With the increasing of blowing ratio, the stagnation pressure loss in the blade passage tended to decrease. The largest decrement of mixed-out loss on the plane of $30 \% \mathrm{C}_{x}$ downstream of TE was $3.56 \%$ compared with the base case without coolant, when the blowing ratio equalled 2.1 . This was explained as the effect of mixing process of coolant and TLV became more and more significant with the increasing of coolant.

Thermal performance of suction surface of blade was presented with cooling effectiveness, heat transfer coefficient increment, NHFR and heat load. With the increasing of blowing ratio, cooling effectiveness became worse as the coolant near the cooling hole was carried away from blade surface. But the heat transfer coefficient increment and NHFR presented different tendency from cooling effectiveness. With the increasing of blowing ratio, heat transfer coefficient increment and NHFR became better. The reason of this phenomenon was that the intensity of TLV became more weakened with the increasing of blowing ratio. At the same time, the inducement of PV derived from boundary layer of casing end wall became stronger. So, the position of TLV became farther away from suction surface. As a result, the interaction of TLV and blade surface was weakened. The overall heat load of $59.1 \% \mathrm{C}_{x}$ spanwise of suction surface was reduced with the increasing of blowing ratio. The largest decrement of heat load was more than $6 \%$ compared with the base case without coolant, when the blowing ratio equalled 2.1 .

\section{References}

[1] Bunker R S. Turbine blade tip design and tip clearance treatment. VKI Lecture Series, 2004.

[2] Hohlfeld E. M., Christophel J. R., Couch E. L., \& Thole K. A. (2003). Predictions of Cooling from Dirt Purge Holes Along the Tip of a Turbine Blade. Volume 5: Turbo Expo 2003, Parts A and B. doi: $10.1115 /$ gt2003-38251

[3] Couch E., Christophel J., Hohlfeld E., Thole K. A., \& Cunha F. J. (2005). Comparison of Measurements and Predictions for Blowing from a Turbine Blade Tip. Journal of Propulsion and Power, 21(2), 335-343. doi: $10.2514 / 1.7238$

[4] Zhou C., \& Hodson H. (2011). The Tip Leakage Flow of an Unshrouded High Pressure Turbine Blade with Tip Cooling. Journal of Turbomachinery, 133(4), 041028. doi:10.1115/1.4001174

[5] Volino R. J. (2017). Control of Tip Leakage in a HighPressure Turbine Cascade Using Tip Blowing. Journal of Turbomachinery, 139(6), 061008. doi:10.1115/1.4035509

[6] Krishnababu S. K., Hodson H. P., Booth G. D., Lock G. D., \& Dawes W. N. (2010). Aerothermal
Investigation of Tip Leakage Flow in a Film Cooled Industrial Turbine Rotor. Journal of Turbomachinery, 132(2), 021016. doi:10.1115/1.3144164

[7] Kwak J. S., \& Han J.-C. (2003). Heat Transfer Coefficients and Film Cooling Effectiveness on the Squealer Tip of a Gas Turbine Blade. Journal of Turbomachinery, 125(4), 648. doi:10.1115/1.1622712

[8] Rezasoltani M., Lu K., Schobeiri M. T., \& Han J.-C. (2014). A Combined Experimental and Numerical Study of the Turbine Blade Tip Film Cooling Effectiveness Under Rotation Condition. Journal of Turbomachinery, $\quad$ 137(5), 051009. doi:10.1115/1.4028745

[9] Newton P. J., Lock G. D., Krishnababu S. K., Hodson H. P., Dawes W. N., Hannis J., \& Whitney C. (2009). Aerothermal Investigations of Tip Leakage Flow in Axial Flow Turbines-Part III: TIP Cooling. Journal of Turbomachinery, 131(1), 011008. doi:10.1115/1.2950060

[10] Zhou C., Hodson H., \& Lock G. (2012). Thermal Performance of Different Cooled Tips in A HighPressure Turbine Cascade. Journal of Propulsion and Power, 28(5), 900-911. doi:10.2514/1.b34299

[11] Tamunobere O., \& Acharya S. (2016). Turbine Blade Tip Film Cooling with Blade Rotation-Part I: Tip and Pressure Side Coolant Injection. Journal of Turbomachinery, $\quad$ 138(9), 091002. doi: $10.1115 / 1.4032672$

[12] Christophel J. R., Thole K. A., \& Cunha F. J. (2005). Cooling the Tip of a Turbine Blade Using Pressure Side Holes-Part I: Adiabatic Effectiveness Measurements. Journal of Turbomachinery, 127(2), 270. doi:10.1115/1.1812320

[13] Christophel J. R., Thole K. A., \& Cunha F. J. (2005). Cooling the Tip of a Turbine Blade Using Pressure Side Holes-Part II: Heat Transfer Measurements. Journal of Turbomachinery, 127(2), 278. doi:10.1115/1.1811096

[14] Gao Z., Narzary D., Mhetras S., \& Han J.-C. (2009). Effect of Inlet Flow Angle on Gas Turbine Blade Tip Film Cooling. Journal of Turbomachinery, 131(3), 031005. doi:10.1115/1.2987235

[15] Arisi A., Phillips J., Ng W. F., Xue S., Moon H. K., \& Zhang L. (2016). An Experimental and Numerical Study on the Aerothermal Characteristics of a Ribbed Transonic Squealer-Tip Turbine Blade With Purge Flow. Journal of Turbomachinery, 138(10), 101007. doi:10.1115/1.4032925

[16] Naik S., Georgakis C., Hofer T., \& Lengani D. (2012). Heat Transfer and Film Cooling of Blade Tips and Endwalls. Journal of Turbomachinery, 134(4), 041004. doi:10.1115/1.4003652

[17] Zhong F. P., \& Zhou C. (2017). Effects of Tip Gap Size on the Aerodynamic Performance of a CavityWinglet Tip in a Turbine Cascade. Journal of Turbomachinery, $139(10), \quad 101009$. doi:10.1115/1.4036677 
[18] Zhou K., \& Zhou C. (2018). Aerodynamic Interaction Between an Incoming Vortex and Tip Leakage Flow in a Turbine Cascade. Journal of Turbomachinery, 140(11), 111004. doi:10.1115/1.4041514

[19] Roache P. J. (1994). Perspective: A Method for Uniform Reporting of Grid Refinement Studies. Journal of Fluids Engineering, 116(3), 405. doi:10.1115/1.2910291

[20] Zhang B., Qiang X. Q., Teng J. F., Lu S. P. (2019). Unsteady Passing Wake Effects on Turbine Blade Tip Aerodynamic and Aerothermal Performance with Film Cooling. Proceedings of ASME Turbo Expo 2019. GT2019-90207 